\title{
ERECTOR SPINAE PLANE BLOCK AND PLACEMENT OF PERINEURAL CATHETER FOR DEVELOPMENTAL HIP DISORDER SURGERY IN CHILDREN
}

\author{
Emil Bosinci ${ }^{1}$, Svetolik Spasić, ${ }^{2,3}$, Maja Mitrović ${ }^{4}$, Marija Stević $^{1,2}$, \\ Irena Simićc ${ }^{4}$ and Dušica Simić ${ }^{1,2}$ \\ ${ }^{1}$ University Children's Hospital, Belgrade, Serbia; \\ ${ }^{2}$ Faculty of Medicine, University of Belgrade, Belgrade, Serbia; \\ ${ }^{3}$ Ljubodrag Buba Mihailović Institute for Pathological Physiology, Belgrade, Serbia; \\ ${ }^{4}$ Klinikum Westfalen, Dortmund, Germany
}

\begin{abstract}
SUMMARY - The ultrasound-guided erector spinae plane (ESP) block is a novel interfascial plane block technique providing analgesic effects in different localizations of the body, in accordance with the level of administration. Although ESP block is usually performed in the thoracic region in pediatric patients, it is possible to achieve ESP block in the lumbar region as well. Postoperative pain management is essential in patients undergoing operative hip treatment, one of the most common procedures in pediatric orthopedic surgery. We report on a case of effective intraoperative analgesia achieved by ultrasound-guided lumbar ESP block and another case of effective intra- and postoperative analgesia accomplished with perineural catheter placement in addition to lumbar ESP block, both performed in children surgically treated for developmental hip disorders.
\end{abstract}

Key words: Erector spinae plane block; Lumbar region; Child

\section{Introduction}

Developmental hip disorder is a dynamic malformation comprised of a spectrum of abnormalities, ranging from unstable hip lesions with a loose capsule to complete dislocation of the femoral head from the anomalous cup. It predominantly affects children, with a higher incidence of 3:1 to 10:1 in female population. The causes are numerous and are divided into two large groups, endogenous and exogenous ${ }^{1}$. Treatment of this condition can be non-operative and operative. Surgical approach falls into two groups, i.e. interventions to correct femoral anteversion and interventions to reorient the acetabulum and reduce its obliquity.

Correspondence to: Emil Bosinci, MD, University Children's Hospital, Tiršova 10, 11000 Belgrade, Serbia

E-mail: ebosinci@gmail.com

Received February 6, 2020, accepted April 8, 2020
Complications of surgical treatment are numerous, but most significant are ischemic necrosis of femoral head and impaired growth of proximal femur. The aforementioned complications are iatrogenic in most cases. Erector spinae plane (ESP) block is a newly described interfascial plane block. ESP block is effective on both visceral and somatic pain. The ultrasound-guided ESP block has been originally described as an approach for thoracic analgesia at the level of the $\mathrm{T} 5$ transverse process $^{2}$. Local anesthetics (LA) block ventral and dorsal rami of spinal nerves, as well as communicant rami that possess sympathetic fibers ${ }^{3}$. The extent of dermatome surface affected by ESP block depends on drug concentration, site of injection and volume of the LA applied. Elkoundi et al. ${ }^{4}$ report on a successfully performed ultrasound-guided ESP block in the region of the L2 transverse process in a 4-year-old girl prior to surgical treatment of hip dysplasia. Balaban et al. ${ }^{5}$ pre- 


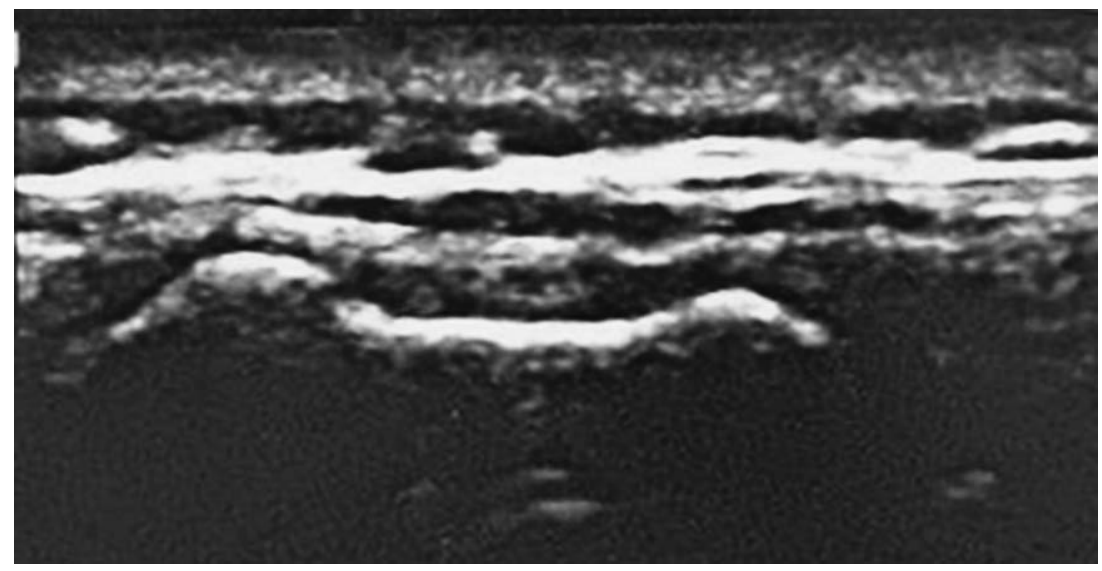

Fig. 1. Ultrasound image of the medial sagittal plane at the L4 vertebra level, clearly verifying the spinous process, which superimposed the hyperechoic radius-shaped structure.

sented a case of a 6-year-old patient having undergone ESP block procedure prior to surgery, without having to be treated postoperatively with opioid analgesics. From the anesthesiologists' point of view, selecting the finest method of analgesia is a primary goal. In this report, we present a case of ESP block implementation and another case of perineural catheter placement in addition to ESP block, both performed in the lumbar region, prior to operative treatment of developmental hip disorder.

\section{Case Reports}

We report on two patient cases; in the first case, a 'single dose' ESP block in the L4 lumbar region was performed in addition to general endotracheal anesthesia (GEA), and in the second case, a perineural catheter was placed on the right side at the L4 level in addition to the 'single dose' ESP block and GEA. Both patients were female and admitted to the Orthopedic Department, University Children's Hospital for an elective surgical procedure.

\section{Case 1}

A 24-month-old female patient (body weight 18 $\mathrm{kg}$ ) with developmental hip disorder and subsequent subluxation was admitted to the hospital for a planned Salter osteotomy. Preoperatively, she was in good general condition, there were no reported allergies or accompanying comorbidities. According to the American Society of Anesthesiologists (ASA), the patient's physical status was classified as ASA PS I. During preoperative preparation of the patient, an hour before the surgical procedure, a broad spectrum antibiotic was administered as prophylaxis and necessary blood products were obtained. Upon routine GEA protocol, 'single dose' ESP block was performed. The patient underwent standard preparation for this procedure, placed in lateral position, and the intervention field was sanitized. Visual guidance during the intervention was obtained by ultrasound (eZono 4000, eZono AG, Jena, Germany). The ultrasound probe was initially placed in the medial sagittal plane at the level of the L4 vertebra, clearly verifying the spinous process, which superimposed the hyperechoic radius-shaped structure (Fig. 1).

Subsequently, the probe was moved laterally parasagittally, verifying the erector spinae muscle layers to

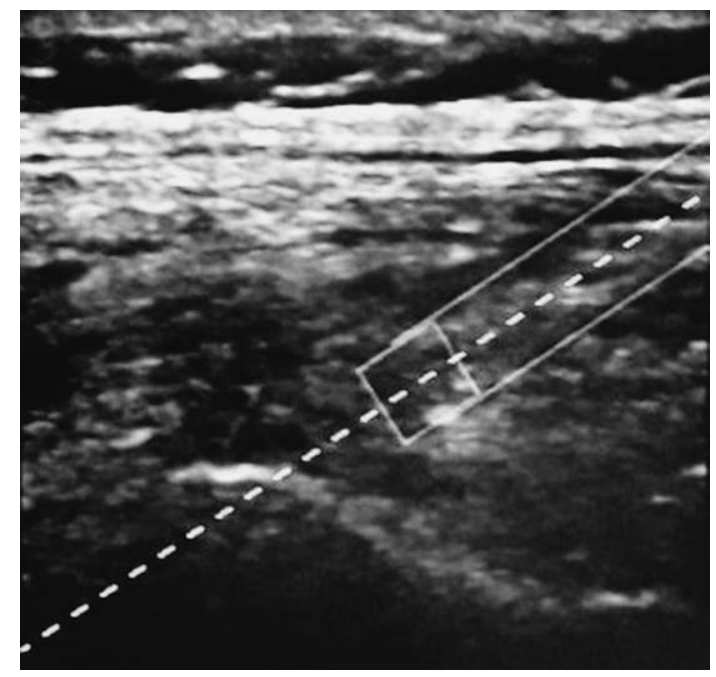

Fig. 2. Ultrasound image of the erector spinae muscle layers and the hyperechoic transverse process of the L4 vertebra immediately below, which has a radius shape. The needle direction is oriented towards the L4 transverse process. 
the right and the transverse process of the L4 vertebra immediately below, which also appeared as a hyperechoic radius-shaped structure. The needle was oriented towards the L4 transverse process (Fig. 2) and, upon hydrodissection, a mixture of lidocaine $2 \% 2$ $\mathrm{mL} / 40 \mathrm{mg}$ and levobupivacaine $0.25 \% 14 \mathrm{~mL} / 36 \mathrm{mg}$ was administered.

Throughout the procedure, vital functions were continuously monitored. During induction of anesthesia, total opioid consumption was $2.5 \mathrm{mcg} / \mathrm{kg}$ fentanyl and ondansetron $0.1 \mathrm{mg} / \mathrm{kg}$, both applied intravenously. The patient was hemodynamically stable during the operation, which lasted for 1.5 hours and upon waking up did not show signs of pain. During postoperative day 0 , there was no need for more analgesia and the patient did not have postoperative nausea and vomiting (PONV) syndrome. During postoperative day 1 , metamizole $(2.5 \mathrm{~g} / 5 \mathrm{~mL})$ in a dose of $1.5 \mathrm{~mL}$ was prescribed as needed at a maximum dosing interval of 8 hours. Seven days after the surgical procedure, the patient was discharged from the hospital without complications.

\section{Case 2}

A 7-year-old female patient (body weight $22 \mathrm{~kg}$ ) was diagnosed with spastic form of cerebral palsy, as she presented with slow psychomotor development and was difficult to feed. Her history revealed previous surgical treatment of the left hip in GEA a few years before, i.e. Pemberton osteotomy and proximal femoral osteotomy, which were followed by severe pain in the hip spreading to the leg, and PONV syndrome. She had regular follow-up visits to a neurologist and physical therapy. The patient also had thrombasthenia with normal platelet count and mildly prolonged prothrombin time and activated partial thromboplastin time. The aforementioned comorbidity was not a contraindication for ESP block and the patient was preoperatively examined by a hematologist. Keeping in mind cerebral palsy the patient presented with and the possibility of a more difficult postoperative recovery, we made a decision to place a perineural catheter in addition to 'single dose' ESP block. Upon administration of GEA, the ESP block procedure was performed in the same manner as described for the patient in case 1. However, different doses of local anesthetics were used, i.e. lidocaine $2 \% 4 \mathrm{~mL} / 80 \mathrm{mg}$, levobupivacaine $0.25 \% 17 \mathrm{~mL} / 40 \mathrm{mg}$ with fentanyl in a dose of 20

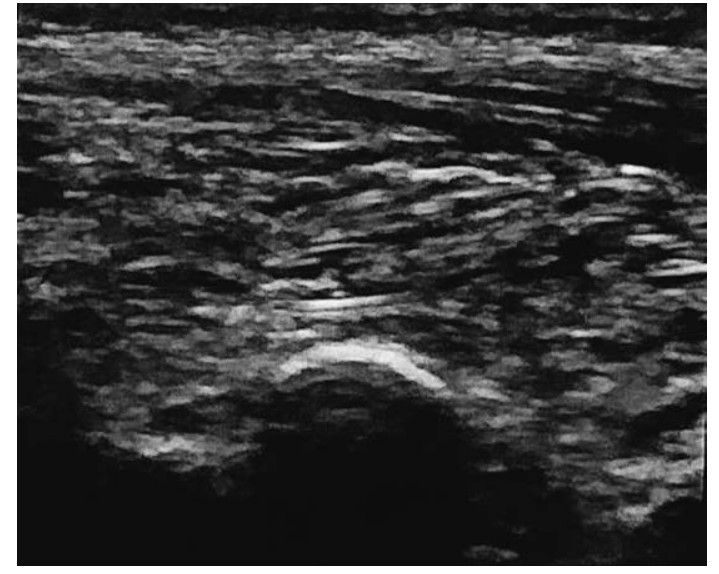

Fig. 3. Perineural catheter placed at the L4 vertebral body level.

mcg. The perineural catheter was placed at the L4 vertebral body level (Fig. 3).

The surgical procedure that followed these interventions lasted for 2 hours. Postoperatively, in the intensive care unit and afterwards on the surgical ward, levobupivacaine $0.125 \%$ was prepared and administered at a rate of $4-8 \mathrm{~mL} /$ hour via perineural catheter connected to an infusion pump. During postoperative day 0 , the patient did not complain of pain, nausea or vomiting. On postoperative day 3 , the perineural catheter was removed. The patient was discharged from the hospital without any complications.

\section{Discussion}

Pediatric patients present a specific population in which multi-modal approach to treatment is often required. A crucial goal in intra- and postoperative pain control is reduction of opioid utilization. The implementation of less invasive techniques of regional anesthesia, namely ESP block rather than epidural or spinal anesthesia, reduces the risk of severe complications such as large hematomas, infections, meningeal injuries, pneumothorax, systemic toxicity of LA, and others. A combination of dexamethasone and levobupivacaine improves postoperative analgesia and extends duration of the block. A meta-analysis of 14 studies showed that the combination of dexamethasone and levobupivacaine for brachial plexus block improved postoperative analgesia without increasing the incidence of complications ${ }^{6}$. To the best of our knowledge, ESP block was, to this instance, mostly used in post- 
operative analgesia concomitantly with paracetamol following laparoscopic interventions and thoracic, abdominal, urologic and orthopedic surgical procedures. In their study, Aksu and Gurkan ${ }^{7}$ have described three approaches to ESP block intervention in pediatric patients, i.e. classic, transverse, and Aksu approach. They also report on the doses of $0.25 \%$ levobupivacaine of $0.5 \mathrm{~mL} / \mathrm{kg}$, with $20 \mathrm{~mL}$ as the maximal dose. They also describe patient protocols by which all patients younger than 15 years received preoperative ESP block, while older children were asked for their consent to perform ESP block. During postoperative care, all patients were treated with $15 \mathrm{mg} / \mathrm{kg}$ of paracetamol intravenously.

Tulgar and Senturk ${ }^{8}$ showed that ESP block could also be performed in geriatric patients burdened with multiple comorbidities and an increased risk of complications during surgical procedures. Lumbar ESP block at the L4 level can be used for effective analgesia in surgical procedures on the pelvis, with high success rates. In addition, the risk of lumbosacral plexus injury is small, since the drugs are applied directly on the bone, i.e. on top of the transverse process of the L4 vertebra ${ }^{9}$. In lower segments of the thoracic vertebral column, transverse processes are shorter and underdeveloped, so ESP block at Th12 level is not advised. The needle used for ESP block is inserted by in-plane technique in craniocaudal or caudocranial direction, depending on the desired distribution of the local anesthetic $^{10}$. Bilateral ESP block can be an appropriate alternative to epidural analgesia because it averts severe hemodynamic complications, hypotension, epidural hemorrhage, and/or epidural abscesses ${ }^{11}$. ESP block ensures effective analgesia in thoracic surgery, which can last for up to 30 hours after ${ }^{12}$. Another case report describes an 11-year-old patient with opioid allergy who was scheduled for laparoscopic cholecystectomy. Given the circumstances, non-opioid analgesia was required, so perioperative and postoperative analgesia was achieved by using ESP block ${ }^{13}$.

The ESP block is a safe and effective procedure for postoperative analgesia which drastically reduces opioid use during various surgical interventions in pediatric patients ${ }^{14}$. Implementation of ESP block for orthopedic surgical procedures in pediatric population has shown remarkable efficacy of this approach in analgesia. Our experience confirms positive effects of ESP block, since postoperative analgesia is satisfactory, without the need for analgesics, nausea and vomiting, with early patient mobilization and shorter hospitalization. It is noteworthy to point out that we used a significantly smaller amounts of opioids intraoperatively. In addition to the results presented, we believe that further studies on the role of ESP block in pediatric patients are necessary.

\section{Conclusion}

Operative treatment of developmental hip disorders is an extensive pediatric surgical approach that carries high risks of acute bleeding, avascular necrosis of the femoral head, and severe postoperative pain that may further aggravate the patient general condition. In these cases, a combination of ESP block and GEA presents an excellent method for achieving adequate analgesia during surgery and maintaining analgesia in the postoperative period. ESP block is a novel, minimally invasive method of regional anesthesia, with very few contraindications and complications. It is also effective in managing acute and chronic pain, thus contributing to additional introductory stability of the patient, reducing opioid use, and may be an excellent choice of analgesia for hip surgery in pediatric population.

\section{References}

1. Clinical practice guideline: early detection of developmental dysplasia of the hip. Committee on Quality Improvement, Subcommittee on Developmental Dysplasia of the Hip. American Academy of Pediatrics. Pediatrics. 2000;105(4 Pt 1):896905. Epub 2000/04/01. doi: 10.1542/peds.105.4.896. PubMed PMID: 10742345.

2. Forero M, Adhikary SD, Lopez H, Tsui C, Chin KJ. The erector spinae plane block: a novel analgesic technique in thoracic neuropathic pain. Reg Anesth Pain Med. 2016;41(5):621-7. Epub 2016/08/09. doi: 10.1097/aap.0000000000000451. PubMed PMID: 27501016.

3. Ivanusic J, Konishi Y, Barrington MJ. A cadaveric study investigating the mechanism of action of erector spinae blockade. Reg Anesth Pain Med. 2018;43(6):567-71. Epub 2018/05/11. doi: 10.1097/aap.0000000000000789. PubMed PMID: 297 46445 .

4. Elkoundi A, Bentalha A, Kettani SEE, Mosadik A, Koraichi AE. Erector spinae plane block for pediatric hip surgery - a case report. Korean J Anesthesiol. 2019;72(1):68-71. Epub 2018/08/25. doi: 10.4097/kja.d.18.00149. PubMed PMID: 30139214; PubMed Central PMCID: PMCPmc6369335.

5. Balaban O, Koculu R, Aydin T. Ultrasound-guided lumbar erector spinae plane block for postoperative analgesia in femur 
fracture: a pediatric case report. Cureus. 2019;11(7):e5148. Epub 2019/09/17. doi: 10.7759/cureus.5148. PubMed PMID: 31523576; PubMed Central PMCID: PMCPmc6741383.

6. Simurina T, Mraovic B, Zupcic M, Graf Zupcic S, Vulin M. Local anesthetics and steroids: contraindications and complications - clinical update. Acta Clin Croat. 2019;58(Suppl 1):53-61. Epub 2019/11/20. doi: 10.20471/acc.2019.58.s1.08. PubMed PMID: 31741560; PubMed Central PMCID: PMCPmc6813483.

7. Aksu C, Gurkan Y. Defining the indications and levels of erector spinae plane block in pediatric patients: a retrospective study of our current experience. Cureus. 2019;11(8):e5348. Epub 2019/10/12. doi: 10.7759/cureus.5348. PubMed PMID: 31602352; PubMed Central PMCID: PMCPmc6779152.

8. Tulgar S, Senturk O. Ultrasound guided erector spinae plane block at L-4 transverse process level provides effective postoperative analgesia for total hip arthroplasty. J Clin Anesth. 2018;44:68. Epub 2017/11/18. doi: 10.1016/j.jclinane.2017. 11.006. PubMed PMID: 29149734.

9. Tulgar S, Selvi O, Senturk O, Ermis MN, Cubuk R, Ozer Z. Clinical experiences of ultrasound-guided lumbar erector spinae plane block for hip joint and proximal femur surgeries. J Clin Anesth. 2018;47:5-6. Epub 2018/03/10. doi: 10.1016/j. jclinane.2018.02.014. PubMed PMID: 29522966.
10. Chin KJ, Adhikary SD, Forero M. Erector spinae plane (ESP) block: a new paradigm in regional anesthesia and analgesia. Curr Anesthesiol Rep. 2019;9(3):271-80. doi: 10.1007/s40140019-00333-0.

11. Restrepo-Garces CE, Chin KJ, Suarez P, Diaz A. Bilateral continuous erector spinae plane block contributes to effective postoperative analgesia after major open abdominal surgery: a case report. A \& A Case Reports. 2017;9(11):319-21. Epub 2017/07/21. doi: 10.1213/xaa.0000000000000605. PubMed PMID: 28727597.

12. Munoz F, Cubillos J, Bonilla AJ, Chin KJ. Erector spinae plane block for postoperative analgesia in pediatric oncological thoracic surgery. Can J Anaesth. 2017;64(8):880-2. doi: 10.1007/ s12630-017-0894-0. PubMed PMID: 28447318.

13. Thomas DT, Tulgar S. Ultrasound-guided erector spinae plane block in a child undergoing laparoscopic cholecystectomy. $\mathrm{Cu}-$ reus. 2018;10(2):e2241. Epub 2018/05/03. doi: 10.7759/cureus.2241. PubMed PMID: 29719743; PubMed Central PMCID: PMCPmc5922508.

14. Niraj G, Zubair T. Continuous erector spinae plane (ESP) analgesia in different open abdominal surgical procedures: a case series. J Anesth Surg. 2018;5(1):57-60. doi: 10.15436/23771364.18.1853. PRI OPERATIVNOM LIJEČENJU RAZVOJNOG POREMEĆAJA KUKA KOD DJECE

\author{
E. Bosinci, S. Spasic, M. Mitrovic, M. Stevic, I. Simić i D. Simić
}

Erector spinae plane (ESP) blok vođen ultrazvukom je nova interfascijalna tehnika blokade koja pruža analgetske učinke u različitim lokalizacijama tijela, u skladu s razinom primjene. Iako se ESP blok obično izvodi u torakalnoj regiji kod pedijatrijskih bolesnika, moguće je postići ESP blok i u lumbalnoj regiji. Poslijeoperacijsko liječenje boli od presudne je važnosti kod bolesnika koji se podvrgavaju operativnom liječenju kuka, što je jedan od najčešćih postupaka u dječjoj ortopedskoj kirurgiji. U dva slučaja postignuta je učinkovita intraoperacijska analgezija ultrazvučno vođenim lumbalnim ESP blokom te učinkovita intra- i poslijeoperacijska analgezija ostvarena postavljanjem perineuralnog katetera uz dodatak lumbalnom ESP bloku kod djece operirane zbog razvojnog poremećaja kuka.

Ključne riječi: Erector spinae plane blok; Lumbalna regija; Djeca 